\section{(2) \\ BRAZIILIAN JOURNAL \\ OF MEDICAL AND BIOLOGICAL RESEARCH}

www.bjournal.com.br
ISSN 0100-879X

Volume 45 (3) 179-290 March 2012

BIOMIEDICAL SCIENCES

AND

CLINICAL INVESTIGATION

Braz J Med Biol Res, March 2012, Volume 45(3) 179-186

Animal models of prenatal immune challenge and their contribution to the study of schizophrenia: a systematic review

D.S. Macêdo, D.P. Araújo, L.R.L. Sampaio, S.M.M. Vasconcelos, P.M.G. Sales, F.C.F. Sousa, J.E. Hallak, J.A. Crippa and A.F. Carvalho

The Brazilian Journal of Medical and Biological Research is partially financed by

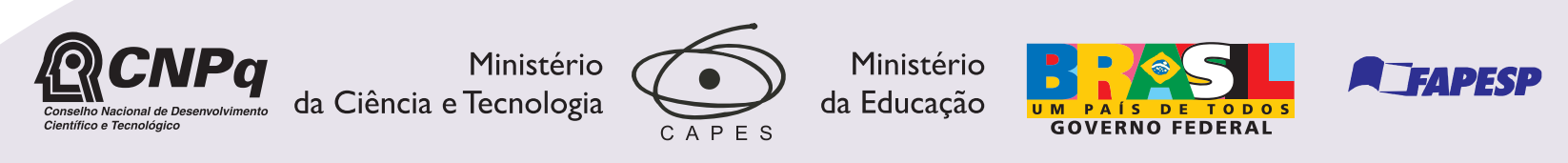

Institutional Sponsors

sumpos
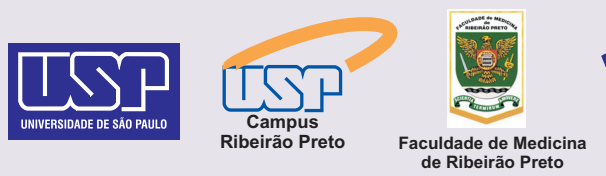

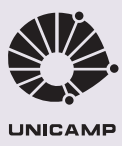

SHIMADZU

Associaçăa
Fundo de Incentivo
à Pesquisa

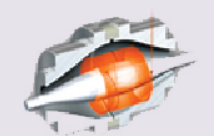

lore High - Performance MS Orbitrap Technology analitica Thermo 


\title{
Animal models of prenatal immune challenge and their contribution to the study of schizophrenia: a systematic review
}

\author{
D.S. Macêdo ${ }^{1}$, D.P. Araújo ${ }^{1}$, L.R.L. Sampaio ${ }^{1}$, S.M.M. Vasconcelos ${ }^{1}$, \\ P.M.G. Sales ${ }^{2}$, F.C.F. Sousa ${ }^{1}$, J.E. Hallak ${ }^{3,4}$, J.A. Crippa ${ }^{3,4}$ and A.F. Carvalho ${ }^{2}$ \\ ${ }^{1}$ Departamento de Fisiologia e Farmacologia, Faculdade de Medicina, \\ Universidade Federal do Ceará, Fortaleza, CE, Brasil \\ ${ }^{2}$ Departamento de Medicina Clínica, Faculdade de Medicina, \\ Universidade Federal do Ceará, Fortaleza, CE, Brasil \\ ${ }^{3}$ Departamento de Neurologia, Psiquiatria e Psicologia Médica, Hospital das Clínicas, \\ Faculdade de Medicina de Ribeirão Preto, Universidade de São Paulo, Ribeirão Preto, SP, Brasil \\ ${ }^{4}$ Instituto Nacional de Ciências e Tecnologia Translacional em Medicina, CNPq, Brasil
}

\begin{abstract}
Prenatal immune challenge (PIC) in pregnant rodents produces offspring with abnormalities in behavior, histology, and gene expression that are reminiscent of schizophrenia and autism. Based on this, the goal of this article was to review the main contributions of PIC models, especially the one using the viral-mimetic particle polyriboinosinic-polyribocytidylic acid (poly-l:C), to the understanding of the etiology, biological basis and treatment of schizophrenia. This systematic review consisted of a search of available web databases (PubMed, SciELO, LILACS, PsycINFO, and ISI Web of Knowledge) for original studies published in the last 10 years (May 2001 to October 2011) concerning animal models of PIC, focusing on those using poly-I:C. The results showed that the PIC model with poly-I:C is able to mimic the prodrome and both the positive and negative/cognitive dimensions of schizophrenia, depending on the specific gestation time window of the immune challenge. The model resembles the neurobiology and etiology of schizophrenia and has good predictive value. In conclusion, this model is a robust tool for the identification of novel molecular targets during prenatal life, adolescence and adulthood that might contribute to the development of preventive and/or treatment strategies (targeting specific symptoms, i.e., positive or negative/cognitive) for this devastating mental disorder, also presenting biosafety as compared to viral infection models. One limitation of this model is the incapacity to model the full spectrum of immune responses normally induced by viral exposure.
\end{abstract}

Key words: Schizophrenia; Animal models; Neurodevelopment; Prenatal immune activation; Poly-I:C

\section{Introduction}

Schizophrenia is a devastating lifetime mental illness that affects $\sim 0.5-1.0 \%$ of the population. The disorder has a heterogeneous course and consists of several symptom dimensions, namely, positive (hallucinations and delusions), negative (e.g., avolition), affective (e.g., depression), and cognitive (e.g., memory deficits) $(1,2)$. Schizophrenia is responsible for $15 \%$ of first medical appointments in psychiatric clinics, as well as $30 \%$ of the occupation of psychiatric wards. The disorder generates high financial costs to health services and to society (3-5).

Epidemiological studies provide compelling evidence that perinatal factors, such as exposure to environmental insults, including maternal exposure to stress, infections and/or immune activation, maternal malnutrition, as well as obstetric complications (e.g., hypoxia), confer a high attributable risk to schizophrenia (6-8).

According to the classic neurodevelopment hypothesis of schizophrenia, relevant genes involved in brain development would be susceptible to gene-environment interactions - mainly during the second gestational trimester - that would lead to disruption of brain development trajectories, limbic disorganization and neurochemical (e.g., monoaminergic)

Correspondence: D.S. Macêdo, Laboratório de Neurofarmacologia, Departamento de Fisiologia e Farmacologia, Universidade Federal do Ceará, Rua Coronel Nunes de Melo, 1127, 60431-270 Fortaleza, CE, Brasil.

Fax: +55-85-3366-8333. E-mail: daniellesm2000@yahoo.com

Received October 8, 2011. Accepted February 10, 2012. Available online March 9, 2012. Published March 19, 2012. 
imbalances $(9,10)$.

The neurodevelopment theory of schizophrenia receives further support from several brain autopsy and neuroimaging studies (11-14). Minimal neuronal cytoarchitecture abnormalities are observed in the brain of schizophrenia patients, with the absence of massive glial proliferation (gliosis), suggesting that damage during brain development contributes to the pathophysiology of this particular disorder $(15,16)$. Several insults that occur during early neurodevelopment phases may impair late postnatal cerebral maturation, ultimately leading to an increase in vulnerability to schizophrenia. According to Nestler and Hyman (17), at least four elements can play an important role in the postnatal brain maturation of schizophrenic individuals: i) maturation of GABAergic interneurons; ii) pruning of glutamatergic synapses; iii) maturation of dopaminergic projections (mainly mesocortical), and iv) differentiation/myelination of oligodendrocytes. All of these elements are associated with the action of novel proteins such as Neuregulin-1 (NRG1) and Disrupted-In-Schizophrenia-1 (DISC-1) (17).

Several experimental models are currently available to test hypotheses about the pathophysiology of schizophrenia $(17,18)$. However, this is a remarkably multifaceted disorder with complex clinical presentations that pose significant challenges to the development of reliable animal models. Therefore, efforts to replicate the schizophrenic syndrome in animals are far from complete, leading to a certain degree of skepticism in the scientific community (19).

The animal models developed for the study of schizophrenia are: i) drug-induced models (e.g., NMDA receptor antagonists - ketamine and apomorphine); ii) lesion-induced preparations (e.g., ventral hippocampal lesion); iii) genetic (e.g., alpha-CaMKII knockout mice), and iv) neurodevelopment approaches (e.g., human influenza virus and rat maternal malnutrition).

Recently, research efforts have been directed at the development of the so-called neurodevelopment models of schizophrenia. Particularly, the prenatal immune challenge (PIC) has generated substantial advances in the field, as it might longitudinally mimic several behavioral and neurobiological aspects of the disorder $(20,21)$.

The objective of the present study was to perform a systematic literature review of relevant articles about PIC schizophrenia models and to discuss their main contributions to the elucidation of the pathophysiology and treatment of schizophrenia. Since there is currently a diversity of PIC models, we decided to focus on the in vivo model of PIC induced by polyriboinosinic-polyribocytidylic acid (poly-l:C), investigating its contributions to the understanding of the biological bases and treatments of schizophrenia.

\section{Methods}

Articles published in English from May 2001 to October 2011 were searched in relevant web datasets (PubMed,
SciELO, LILACS, PsycINFO, and ISI Web of Knowledge). Search terms included combinations of the following: 'schizophrenia and prenatal immune challenge'; 'prenatal immune challenge and animal model'; 'poly-I:C and schizophrenia', and 'schizophrenia and animal model'.

The search covered original articles. However, reference lists of reviews and original articles were hand-searched for additional references. Conference abstracts were not included. Two authors performed the search independently (DSM and DPA) and relevant articles were selected by three authors (AFC, DSM, and DPA). To prevent biases, inclusion criteria were pre-specified as the following: i) development of schizophrenia by the administration of poly-I:C injection during pregnancy in rodents; ii) experimental data of at least one endophenotype for schizophrenia (for more details, see Gottesman and Gould (22) and Amann et al. (23), and iii) inclusion of a control group in the study design. The search retrieved 45 articles, 30 of which contemplated the inclusion criteria.

To facilitate the discussion of the main findings, this article was organized according to the following topics: 1) general presentation of the models and their contributions to the understanding of the etiology of schizophrenia; 2) contributions of the poly-I:C model to the understanding of the biological bases of schizophrenia, and 3) contributions of the poly-I:C model to the treatment of schizophrenia.

\section{Discussion}

\section{General presentation of the models and their contributions to the understanding of the etiology of schizophrenia}

The animal PIC models developed to date are: experimental models of virus exposure, such as human influenza (10) and Borna virus (24), as well as those that employ cytokine-releasing agents, such as lipopolysaccharide (LPS) bacterial endotoxin (25) or the viral mimetic particle poly-I:C (26).

The prenatal influenza infection model seems to be useful in the investigation of known epidemiological relationships between exposure to prenatal viral infection and the heightened risk of schizophrenia-related psychoses in the offspring (27). This model mimics the behavioral and morphological changes that follow schizophrenia, since it relies on one of the most well-known environmental risk factors implicated in its etiology $(8,28)$. The influenza infection model has good face and construct validity for schizophrenia-like brain and behavioral pathology.

The cytokine-release models were developed to measure how maternal and/or fetal cytokine imbalance would act as core mediators of the association between maternal infection and the development of postnatal behavioral and cerebral pathology (29). These models are induced through the prenatal exposure of animal rodents (female rats or mice) in specific gestational stages to diverse immunologic 
stimuli, such as viruses (24), poly-I:C (30), or LPS (31). Such models are having a great impact on the search for possible neurodevelopmental and neuroimmunologic causes of complex human disorders like schizophrenia and autism (32). Therefore, PIC models might guide the identification of underlying neurobiological mechanisms enrolled in geneenvironment and environment-environment interactions relevant to the etiology of schizophrenia $(33,34)$.

\section{Contributions of the poly-I:C model to the understanding of the biological bases of schizophrenia}

Poly-I:C is a synthetic analogue of the viral doublestranded RNA. The injection of this compound leads to the activation of pro-inflammatory cytokines for a limited time by the activation of Toll-like receptors 3 (TLR3) (35). Thus, poly-I: $C$ is a strong interferon (IFN) inducer, mostly of the IFN- $\alpha$ and IFN- $\beta$ types $(36,37)$. The injection of poly-I:C mimics the acute phase response to a viral infection

Animal studies suggest that the prenatal injection of poly-l:C elicits subcortical dopaminergic hyperfunction and cognitive impairment in the offspring, representing a neurodevelopmental animal model of schizophrenia (38).

Within the spectrum of behavioral changes, prenatal poly-I:C injections have been reported to induce severe changes in various schizophrenia-related endophenotypes, such as: i) sensorimotor gating deficits in adult rat offspring (39-41); ii) latent inhibition disruption only in adulthood (42); iii) postpubertal emergence of enhanced sensitivity to MK801 and amphetamine-induced hyperlocomotion $(43,44)$, and iv) morphofunctional alterations in the hippocampus and the entorhinal cortex in adult offspring, consistent with the well-documented mesolimbic dopaminergic and temporolimbic neuropathology of schizophrenia (43). Rats injected with poly-I:C develop anxiety-related behaviors, as well as impaired object recognition memory (45) and social behavior dysfunction, when compared to controls (40). The occurrence of behavioral endophenotypes mainly in adulthood is consistent with the later onset of schizophrenia symptoms seen in clinical settings (46).

Prenatal poly-I:C immune challenges in the middle and late gestational phases lead to a quantitative increase in mesencephalic dopaminergic neurons in the fetal brain (30). This effect is followed by several gene expression changes related to the developmental course of dopaminergic neurons, including the sonic hedgehog (ShhN) and fibroblastic growth factor 8 (FGF-8), as well as transcription factors like nuclear receptor related 1 protein (Nurr1) and pituitary homeobox 3 (Pitx3) $(30,47)$. The ShhN and FGF-8 genes, as well as the transcription factors Nurr1 and Pitx3, are essential for the generation, differentiation, and maintenance of midbrain dopamine (DA) cells during embryonic development (48).

Recently, following prenatal immune activation, a decrease in NMDA receptor function and elevated basal extracellular glutamate in the prefrontal cortex was demon- strated. Together, these are two key features of the NMDA glutamate receptor hypofunction model of schizophrenia, occurring during late adolescence (49).

Maternal exposure to poly-I:C significantly increased tumor necrosis factor- $\alpha$ (TNF- $\alpha$ ) protein levels in the maternal plasma and placenta, with no alterations in fetal brain, while brain-derived neurotrophic factor (BDNF) and nerve growth factor (NGF) levels decreased in the placenta and fetal liver/spleen. In the neonatal whole brain, TNF- $\alpha$ was decreased while NGF and BDNF were unchanged at 1 and 7 days after birth (50). These changes represent potential mechanisms by which maternal infection can alter neuron development and increase the risk for neurodevelopment disorders.

It is important to state that this model allows the recognition of critical gestational periods of exposure to PIC that specifically contribute to the development of postnatal changes related to the onset of schizophrenia. The gestational period of rodents is 21 days on average. The major deficits in pre-pulse inhibition (a behavioral test to evaluate sensorimotor gating, one of the most replicated schizophrenia endophenotypes) were found mainly in animals submitted to PIC on the 9th gestational day (GD9) $(30,51-53)$, which is equivalent to an early/middle gestational exposure.

According to Meyer et al. (20), the early/middle gestational exposure of mice (GD9) impaired sensorimotor gating and decreased dopaminergic $D_{1}$ receptors located in the pre-frontal cortex (PFC) of the offspring, whereas the exposure in the late gestational phase (GD17) impaired working memory and enhanced locomotor changes induced by the NMDA receptor antagonist dizocilpine. Furthermore, a decrease in the expression of subunit 1 of NMDA hippocampal receptors was found. However, the same study has shown that the potentiation of amphetamine-induced hyperlocomotion and a reduction of PFC neurons that expressed reelin and parvalbumin (GABAergic neurons) occurred independently of the prenatal exposure period. Such exposure periods correspond to the end of the first trimester (GD9) and middle/late phase of the second trimester (GD17) in humans (54). Thus, these data demonstrate that the exposure on GD9 generates phenotypes predominantly related to positive symptoms, whereas exposure on GD15 or GD17 is more suited for the study of behavioral correlates of negative/cognitive symptoms, since adult offspring also presented histopathological abnormalities in the parahippocampal consistent with evidence that this is a point at which the parahippocampal region undergoes neurogenesis $(42,43)$ and also in the cerebellum (26). A retarded myelination and axonal abnormalities in early postnatal stages caused by maternal immune activation were also detected (55) (Figure 1).

Available evidence suggests, therefore, that the PIC in early/middle gestational phases can lead to dysfunctions over multiple neuropsychological domains (e.g., sensorimo- 
tor gating and spatial working memory) (20). This symptomatic heterogeneity may be associated with the impairment of fundamental neurodevelopmental processes, such as cellular proliferation and differentiation triggered by early inflammation in the fetal brain, leading to abnormalities in subsequent cellular migration, synaptogenesis and maturation of synapses $(52,56)$. Indeed, inflammatory events occurring in the initial phase of fetal brain development can result in even more severe damage when compared to exposure that occurs later in gestation, culminating with multiple postnatal dysfunctions and symptomatic heterogeneity, as observed in schizophrenia and autism (57).

In addition to the findings of deleterious effects of direct inflammatory challenges, results exist showing that healthy control animals reared by foster immune-challenged mothers are associated with the occurrence of learning disabilities of early and late onset (58). This suggests that maternal stress during pregnancy somehow affects postpartum maternal behavior and underscores the importance of future research along this line.

These data suggest that the precise periods of prenatal immune challenges influence the susceptibility to distinct behavioral and/or cognitive symptoms that emerge in adult life and draw attention to the temporal link between PIC and the etiology of these disorders (see Table 1).

\section{Contributions of the poly-I:C model to the treatment of schizophrenia}

Prenatal poly-l:C injection elicits changes similar to those observed in schizophrenia that are only fully manifested in adult offspring. In rodents, the prepubertal stage - also known as periadolescence - can be assessed on postnatal days 28-35 (PND28-35), whereas on PND56 the postpubertal period begins (67). Based on the fact that schizophrenia symptoms commonly start in late adolescence and early adult life, this model might provide a valuable means to assess the effects of preventive strategies by the administration of drugs during the prepubertal period (i.e., prodrome), as well as after the complete development of schizophrenia symptoms in adult life. In other words, it enables the study of preventive and therapeutic approaches to schizophrenia. Another highlight of this model is the possibility of studying drugs treating the main dimension of schizophrenia, since the exposure to the viral particle on GD9 is associated with the development of endophenotypes related to positive symptoms in the offspring, while the exposure on GD17 can be useful to study the negative and cognitive symptoms of schizophrenia (20) (Figure 1).

A recently published article has shown that chronic injection of antipsychotics (haloperidol and clozapine) or the antidepressant fluoxetine during periadolescence blocked the onset of psychotic symptoms in animals predisposed to schizophrenia by PIC exposure on GD9. The same study revealed several negative influences of early pharmacological intervention on normal behavioral development of control animals (68). These data suggest that the careful selection of at-risk individuals (psychopathologically and genetically) is necessary, since preventive treatment of individuals without real liability to develop the disorder might result in long-lasting deleterious behavioral effects. The admin-

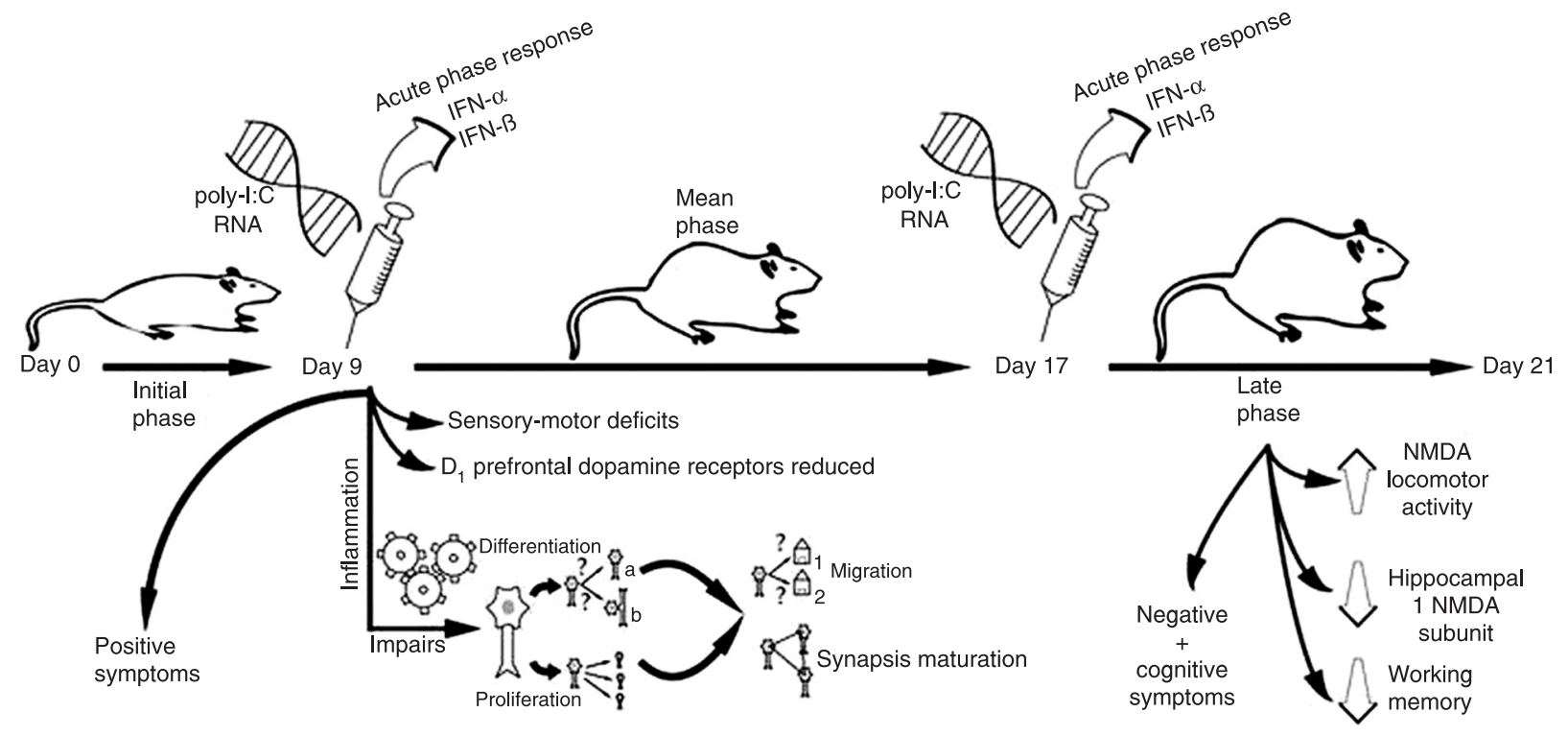

Figure 1. Prenatal exposure to polyriboinosinic-polyribocytidylic acid (poly-I:C) during the early/middle gestational period (gestational day 9 - GD9) generates phenotypes related to positive symptoms. The exposure on GD17 (late gestational period) is related to the occurrence of behavioral correlates of negative/cognitive symptoms of the disorder. 
Table 1. Main contributions of the poly-l:C model to the study of the physiopathology of schizophrenia.

\begin{tabular}{|c|c|c|c|}
\hline Reference & $\begin{array}{l}\text { Gestational day } \\
\text { challenge }\end{array}$ & Main behavioral findings & Main neurobiological findings \\
\hline Meyer et al., 2005 (51) & 9 & $\begin{array}{l}\text { Behavioral deficits in adulthood (PPI, LI, } \\
\text { spatial working memory, enhanced behavioral } \\
\text { response to amphetamine) }\end{array}$ & $\begin{array}{l}\text { Increase of IL-10 at } 1 \text { and } 6 \mathrm{~h} \text { post-injection, increase } \\
\text { of IL-1 } \beta \text { at } 12 \mathrm{~h} \text { post-injection }\end{array}$ \\
\hline Meyer et al., 2006 (57) & $6,9,13$, or 17 & GD6, GD9 or GD13 LI deficiency & GD17 - elevation of the IL-10/TNF ratio \\
\hline Meyer et al., 2006 (58) & 9 & $\begin{array}{l}\text { Postpubertal LI disruption, pre- and } \\
\text { postpubertal loss of LI in control animals } \\
\text { adopted by poly-I:C-treated surrogate mothers }\end{array}$ & - \\
\hline Fortier et al., 2007 (31) & $\begin{array}{l}10-11,15-16 \text { or } \\
18-19\end{array}$ & No significant effect on PPI & - \\
\hline Smith et al., 2007 (59) & 12.5 & $\begin{array}{l}\text { Co-administration of anti-IL- } 6 \text { antibody } \\
\text { prevents the PPI, LI, and exploratory and } \\
\text { social deficits and normalizes the associated } \\
\text { changes in gene expression in the brains of } \\
\text { adult offspring }\end{array}$ & - \\
\hline Meyer et al., 2008 (20) & 9 or 17 & $\begin{array}{l}\text { GD9 - impairment of sensorimotor gating; } \\
\text { GD17 - impairment of working memory, } \\
\text { potentiation of locomotor reaction to NMDA } \\
\text { antagonists; time-independent locomotor } \\
\text { reaction to a dopamine agonist }\end{array}$ & $\begin{array}{l}\text { GD9 - reduction of prefrontal D1 receptors in adulthood; } \\
\text { GD17 - reduced hippocampal NMDA-receptor subunit } \\
\text { expression; time independent reduction in reelin and } \\
\text { parvalbumin-expressing prefrontal neurons }\end{array}$ \\
\hline Meyer et al., $2008(30)$ & 9 & - & $\begin{array}{l}\text { Increase in the number of mesencephalic dopamine neurons } \\
\text { in the fetal brain at middle/late gestation; changes in fetal } \\
\text { expression of genes involved in dopamine neuron generation, } \\
\text { differentiation and maintenance (ShhN, FGF-8) and } \\
\text { transcription factors Nurr1 and Pitx3 }\end{array}$ \\
\hline Winter et al., 2009 (53) & 9 & - & $\begin{array}{l}\text { Increased levels of DA and its major metabolites in the lateral } \\
\text { globus pallidus and prefrontal cortex in adult brain; decreased } \\
\text { serotonin in the hippocampus, nucleus accumbens and lateral } \\
\text { globus pallidus; reduction of taurine in the hippocampus }\end{array}$ \\
\hline Li et al., 2009 (34) & 9 or 17 & GD9 - disruption in PPI & $\begin{array}{l}\text { GD9 - enlargement of lateral ventricles in adulthood; } \\
\text { GD17 - expansion of 4th ventricle volume }\end{array}$ \\
\hline Li et al., 2010 (60) & 9 or 17 & - & GD9 - alterations in neuronal myelination \\
\hline Bitanihirwe et al., 2010 (61) & 17 & $\begin{array}{l}\text { Male and female offspring: deficits in social } \\
\text { interaction, anhedonic behavior, alterations } \\
\text { in locomotor response to apomorphine. Male } \\
\text { offspring only: enhanced LI }\end{array}$ & Sex-specific changes in neurotransmitter levels \\
\hline Cardon et al., $2010(62)$ & - & $\begin{array}{l}\text { Abnormal PPI with delayed appearance found } \\
\text { in congenitally immune-deficient mice (severe } \\
\text { combined immune deficient, SCID), reverted } \\
\text { by immune reconstitution }\end{array}$ & $\begin{array}{l}\text { Impairment of both hippocampal neurogenesis and } \\
\text { expression of the gene encoding kisspeptin (Kiss } 1)^{*} \\
\text { manifested in adulthood }\end{array}$ \\
\hline Dickerson et al., 2010 (63) & - & $\begin{array}{l}\text { Significant reductions in mPFC-HPC EEG } \\
\text { coherence correlated with decreased prepulse } \\
\text { inhibition of startle }\end{array}$ & - \\
\hline Oh-Nishi et al., 2010 (64) & 15 and 17 & - & $\begin{array}{l}\text { Synaptic dysfunction without neuronal loss in the hippocampus } \\
\text { of juvenile offspring; decreased synaptophysin expression }\end{array}$ \\
\hline De Miranda et al., 2010 (65) & 16 & $\begin{array}{l}\text { Impaired neonatal locomotor development } \\
\text { and abnormal sensorimotor gating responses } \\
\text { in adult offspring }\end{array}$ & $\begin{array}{l}\text { Inhibited embryonic neuronal stem cell replication and } \\
\text { population of the superficial layers of the neocortex by } \\
\text { neurons; effects were dependent on Toll-like receptor } 3 \text { (TLR3) }\end{array}$ \\
\hline Hsiao and Patterson, 2011 (66) & 12.5 & - & $\begin{array}{l}\text { Increased IL- } 6 \text { mRNA as well as maternally derived IL- } 6 \\
\text { protein in the placenta }\end{array}$ \\
\hline
\end{tabular}

The table summarizes the main findings using polyriboinosinic-polyribocytidylic acid (poly-l:C) on different gestational days (GD) in rodents and the behavioral and neurochemical pre- and post-natal alterations. PPI = prepulse inhibition of the acoustic startle reflex (i.e., reduction of startle reaction to a startle-eliciting stimulus [pulse] when it is shortly preceded by a weak stimulus [prepulse], a measure of sensorimotor gating); $\mathrm{LI}=$ latent inhibition (i.e., a form of selective associative learning considered to index an organism's capacity to ignore irrelevant stimulus); IL-10 = interleukin-10; IL-1 $=$ interleukin 1-beta; TNF = tumor necrosis factor; ShhN = sonic hedgehog gene; FGF-8 = fibroblast growth factor 8; DA = dopamine; Nurr1 = nuclear receptor-related 1 protein; Pitx3 = pituitary homeobox 3; $\mathrm{HPC}=$ hippocampus; $\mathrm{mPFC}=$ medial prefrontal cortex; NMDA $=\mathrm{N}$-methyl-D-aspartate. ${ }^{*}$ Kisspeptin is a protein that triggers the cascade of biochemical changes leading to puberty.

istration of risperidone during the periadolescence period of animals prevented both ventricular enlargement and reduction of hippocampal size in adult offspring, two of the most common brain abnormalities observed in schizophrenia (69). Risperidone, paliperidone (70), haloperidol (43), and clozapine $(43,71)$ prevented the behavioral changes observed in adult animals submitted to PIC between GD14 and GD15, showing that this model predicts responsiveness to antipsychotic drugs.

Risperidone and paliperidone treatment beginning 
at the periadolescent period lowered basal glutamate in offspring of poly-I:C-treated dams to levels similar to the offspring of saline-treated dams (49), also stabilizing the response to amphetamine exposure persisting into early adulthood (70).

Although more studies are needed to establish the real predictive validity of the model, these data raise the possibility that, in the near future, the PIC model might be a valuable tool to test antipsychotic drugs, as well as compounds that might prevent the onset of schizophrenia throughout various developmental stages.

\section{Concluding comments}

The PIC models - especially the poly-l:C model discussed in further detail in this article - are capable of mimicking several aspects of the schizophrenia syndrome in a neurodevelopmentally oriented approach, reproducing behavioral abnormalities as well as some genetic and neurochemical alterations present in schizophrenia, which may contribute to 1 ) the study of prenatal and postnatal brain dysfunction after

\section{References}

1. McGrath J, Saha S, Welham J, El Saadi O, MacCauley C, Chant D. A systematic review of the incidence of schizophrenia: the distribution of rates and the influence of sex, urbanicity, migrant status and methodology. BMC Med 2004; 2: 13.

2. Saha $S$, Chant $D$, Welham J, McGrath J. A systematic review of the prevalence of schizophrenia. PLoS Med 2005; 2: e141.

3. Lara D, Gama C, Abreu P. Esquizofrenia. In: Kapczinski F, Quevedo J, Izquierdo I (Editors), Bases biológicas dos transtornos psiquiátricos. Porto Alegre: Artmed; 2004. p 285.

4. Kissling W, Hoffler J, Seemann U, Muller P, Ruther E, Trenckmann $U$, et al. [Direct and indirect costs of schizophrenia]. Fortschr Neurol Psychiatr 1999; 67: 29-36.

5. Haro JM, Kamath SA, Ochoa S, Novick D, Rele K, Fargas A, et al. The Clinical Global Impression-Schizophrenia scale: a simple instrument to measure the diversity of symptoms present in schizophrenia. Acta Psychiatr Scand Suppl 2003; 16-23.

6. Clarke MC, Harley M, Cannon M. The role of obstetric events in schizophrenia. Schizophr Bull 2006; 32: 3-8.

7. Pearce BD. Schizophrenia and viral infection during neurodevelopment: a focus on mechanisms. Mol Psychiatry 2001; 6: 634-646.

8. Brown AS, Derkits EJ. Prenatal infection and schizophrenia: a review of epidemiologic and translational studies. $A m \mathrm{~J}$ Psychiatry 2010; 167: 261-280.

9. Weinberger DR. From neuropathology to neurodevelopment. Lancet 1995; 346: 552-557.

10. Fatemi SH, Folsom TD. The neurodevelopmental hypothesis of schizophrenia, revisited. Schizophr Bull 2009; 35: 528548.

11. Le-Niculescu H, Balaraman Y, Patel S, Tan J, Sidhu K, Je- exposure to immune challenges across different gestational stages; 2) provide evidence for the neurodevelopment and neuroimmunologic basis of this disorder; 3 ) enable the study of antipsychotic drugs in a preventive (prenatal life and prodrome) and therapeutic approach; 4) permit the study of medications targeting specific symptoms (i.e., positive or negative/cognitive). One advantage of this model is its biosafety as compared to viral infection models. The main disadvantages of this model are the limited duration of the immune response as compared to viral infection models and the non-mimicking of the precise immunological insults occurring in the human environment. Put differently, it fails to model the full spectrum of immune responses normally induced by viral exposure.

Thus, the poly-l:C model might open new avenues for the identification of novel molecular targets and the eventual preclinical development of new treatments for the disorder. In particular, the search for effective prevention strategies (e.g., at the prodrome) might benefit from the use of this model. rome $\mathrm{RE}$, et al. Towards understanding the schizophrenia code: an expanded convergent functional genomics approach. Am J Med Genet B Neuropsychiatr Genet 2007; 144B: 129-158.

12. Andreasen NC. A unitary model of schizophrenia: Bleuler's "fragmented phrene" as schizencephaly. Arch Gen Psychiatry 1999; 56: 781-787.

13. Trzesniak C, Kempton MJ, Busatto GF, de Oliveira I, Galvaode Almeida A, Kambeitz J, et al. Adhesio interthalamica alterations in schizophrenia spectrum disorders: A systematic review and meta-analysis. Prog Neuropsychopharmacol Biol Psychiatry 2011; 35: 877-886.

14. Trzesniak C, Oliveira IR, Kempton MJ, Galvao-de Almeida A, Chagas MH, Ferrari MC, et al. Are cavum septum pellucidum abnormalities more common in schizophrenia spectrum disorders? A systematic review and meta-analysis. Schizophr Res 2011; 125: 1-12.

15. Harrison PJ. Brains at risk of schizophrenia. Lancet 1999; 353: 3-4.

16. Schnieder TP, Dwork AJ. Searching for neuropathology: gliosis in schizophrenia. Biol Psychiatry 2011; 69: 134-139.

17. Nestler EJ, Hyman SE. Animal models of neuropsychiatric disorders. Nat Neurosci 2010; 13: 1161-1169.

18. Moore $\mathrm{H}$. The role of rodent models in the discovery of new treatments for schizophrenia: updating our strategy. Schizophr Bull 2010; 36: 1066-1072.

19. Salgado JV, Hetem LA, Sandner G. [Experimental models of schizophrenia - a review]. Rev Bras Psiquiatr 2006; 28: 135-141.

20. Meyer U, Nyffeler M, Yee BK, Knuesel I, Feldon J. Adult brain and behavioral pathological markers of prenatal immune challenge during early/middle and late fetal development in mice. Brain Behav Immun 2008; 22: 469-486. 
21. Meyer U, Feldon J. To poly(I:C) or not to poly(I:C): Advancing preclinical schizophrenia research through the use of prenatal immune activation models. Neuropharmacology 2012; 62: 1308-1321.

22. Gottesman II, Gould TD. The endophenotype concept in psychiatry: etymology and strategic intentions. Am J Psychiatry 2003; 160: 636-645.

23. Amann LC, Gandal MJ, Halene TB, Ehrlichman RS, White $\mathrm{SL}, \mathrm{McC}$ arren HS, et al. Mouse behavioral endophenotypes for schizophrenia. Brain Res Bull 2010; 83: 147-161.

24. Lancaster K, Dietz DM, Moran TH, Pletnikov MV. Abnormal social behaviors in young and adult rats neonatally infected with Borna disease virus. Behav Brain Res 2007; 176: 141148.

25. Borrell J, Vela JM, Arevalo-Martin A, Molina-Holgado E, Guaza C. Prenatal immune challenge disrupts sensorimotor gating in adult rats. Implications for the etiopathogenesis of schizophrenia. Neuropsychopharmacology 2002; 26: 204215.

26. Shi L, Smith SE, Malkova N, Tse D, Su Y, Patterson PH. Activation of the maternal immune system alters cerebellar development in the offspring. Brain Behav Immun 2009; 23: 116-123.

27. Brown AS, Susser ES. In utero infection and adult schizophrenia. Ment Retard Dev Disabil Res Rev 2002; 8: 51-57.

28. Moreno JL, Kurita M, Holloway T, Lopez J, Cadagan R, Martinez-Sobrido $\mathrm{L}$, et al. Maternal influenza viral infection causes schizophrenia-like alterations of 5-HTA and mGlu receptors in the adult offspring. J Neurosci 2011; 31: 18631872.

29. Meyer U, Feldon J. Neural basis of psychosis-related behaviour in the infection model of schizophrenia. Behav Brain Res 2009; 204: 322-334.

30. Meyer U, Engler A, Weber L, Schedlowski M, Feldon J. Preliminary evidence for a modulation of fetal dopaminergic development by maternal immune activation during pregnancy. Neuroscience 2008; 154: 701-709.

31. Fortier ME, Luheshi GN, Boksa P. Effects of prenatal infection on prepulse inhibition in the rat depend on the nature of the infectious agent and the stage of pregnancy. Behav Brain Res 2007; 181: 270-277.

32. Meyer U, Feldon J, Dammann O. Schizophrenia and autism: both shared and disorder-specific pathogenesis via perinatal inflammation? Pediatr Res 2011; 69: 26R-33R.

33. Vuillermot S, Weber L, Feldon J, Meyer U. A longitudinal examination of the neurodevelopmental impact of prenatal immune activation in mice reveals primary defects in dopaminergic development relevant to schizophrenia. J Neurosci 2010; 30: 1270-1287.

34. Li Q, Cheung C, Wei R, Hui ES, Feldon J, Meyer U, et al. Prenatal immune challenge is an environmental risk factor for brain and behavior change relevant to schizophrenia: evidence from MRI in a mouse model. PLoS One 2009; 4: e6354.

35. Wang T, Town T, Alexopoulou L, Anderson JF, Fikrig E, Flavell RA. Toll-like receptor 3 mediates West Nile virus entry into the brain causing lethal encephalitis. Nat Med 2004; 10 : 1366-1373.

36. Alexopoulou L, Holt AC, Medzhitov R, Flavell RA. Recognition of double-stranded RNA and activation of NF-kappaB by Toll-like receptor 3. Nature 2001; 413: 732-738.

37. Takeuchi $\mathrm{O}$, Hemmi H, Akira S. Interferon response induced by Toll-like receptor signaling. J Endotoxin Res 2004; 10 : 252-256.

38. Ozawa K, Hashimoto K, Kishimoto T, Shimizu E, Ishikura H, lyo M. Immune activation during pregnancy in mice leads to dopaminergic hyperfunction and cognitive impairment in the offspring: a neurodevelopmental animal model of schizophrenia. Biol Psychiatry 2006; 59: 546-554.

39. Shi L, Fatemi SH, Sidwell RW, Patterson PH. Maternal influenza infection causes marked behavioral and pharmacological changes in the offspring. J Neurosci 2003; 23: 297-302.

40. Ibi D, Nagai T, Kitahara $Y$, Mizoguchi $H$, Koike $H$, Shiraki A, et al. Neonatal polyl:C treatment in mice results in schizophrenia-like behavioral and neurochemical abnormalities in adulthood. Neurosci Res 2009; 64: 297-305.

41. Wolff AR, Bilkey DK. Immune activation during mid-gestation disrupts sensorimotor gating in rat offspring. Behav Brain Res 2008; 190: 156-159.

42. Zuckerman L, Weiner I. Post-pubertal emergence of disrupted latent inhibition following prenatal immune activation. Psychopharmacology 2003; 169: 308-313.

43. Zuckerman L, Rehavi M, Nachman R, Weiner I. Immune activation during pregnancy in rats leads to a postpubertal emergence of disrupted latent inhibition, dopaminergic hyperfunction, and altered limbic morphology in the offspring: a novel neurodevelopmental model of schizophrenia. Neuropsychopharmacology 2003; 28: 1778-1789.

44. Zuckerman L, Weiner I. Maternal immune activation leads to behavioral and pharmacological changes in the adult offspring. J Psychiatr Res 2005; 39: 311-323.

45. Ito HT, Smith SE, Hsiao E, Patterson PH. Maternal immune activation alters nonspatial information processing in the hippocampus of the adult offspring. Brain Behav Immun 2010; 24: 930-941.

46. Gogtay N, Vyas NS, Testa R, Wood SJ, Pantelis C. Age of onset of schizophrenia: perspectives from structural neuroimaging studies. Schizophr Bull 2011; 37: 504-513.

47. Meyer U, Murray PJ, Urwyler A, Yee BK, Schedlowski M, Feldon J. Adult behavioral and pharmacological dysfunctions following disruption of the fetal brain balance between pro-inflammatory and IL-10-mediated anti-inflammatory signaling. Mol Psychiatry 2008; 13: 208-221.

48. Saucedo-Cardenas O, Quintana-Hau JD, Le WD, Smidt MP, Cox JJ, De Mayo F, et al. Nurr1 is essential for the induction of the dopaminergic phenotype and the survival of ventral mesencephalic late dopaminergic precursor neurons. Proc Natl Acad Sci U S A 1998; 95: 4013-4018.

49. Roenker NL, Gudelsky G, Ahlbrand R, Bronson SL, Kern JR, Waterman $\mathrm{H}$, et al. Effect of paliperidone and risperidone on extracellular glutamate in the prefrontal cortex of rats exposed to prenatal immune activation or MK-801. Neurosci Lett 2011; 500: 167-171.

50. Gilmore JH, Jarskog LF, Vadlamudi S. Maternal poly-I:C exposure during pregnancy regulates TNF alpha, BDNF, and NGF expression in neonatal brain and the maternal-fetal unit of the rat. $J$ Neuroimmunol 2005; 159: 106-112.

51. Meyer U, Feldon J, Schedlowski M, Yee BK. Towards an immuno-precipitated neurodevelopmental animal model of schizophrenia. Neurosci Biobehav Rev 2005; 29: 913-947.

52. Meyer U, Nyffeler M, Engler A, Urwyler A, Schedlowski M, Knuesel I, et al. The time of prenatal immune challenge determines the specificity of inflammation-mediated brain and 
behavioral pathology. J Neurosci 2006; 26: 4752-4762.

53. Winter C, Djodari-Irani A, Sohr R, Morgenstern R, Feldon J, Juckel $\mathrm{G}$, et al. Prenatal immune activation leads to multiple changes in basal neurotransmitter levels in the adult brain: implications for brain disorders of neurodevelopmental origin such as schizophrenia. Int J Neuropsychopharmacol 2009; 12: $513-524$.

54. Kaufman MH. The atlas of mouse development. London: Academic Press; 2003

55. Makinodan M, Tatsumi K, Manabe T, Yamauchi T, Makinodan $\mathrm{E}$, Matsuyoshi $\mathrm{H}$, et al. Maternal immune activation in mice delays myelination and axonal development in the hippocampus of the offspring. J Neurosci Res 2008; 86: 2190-2200.

56. Soumiya H, Fukumitsu H, Furukawa S. Prenatal immune challenge compromises development of upper-layer but not deeper-layer neurons of the mouse cerebral cortex. $J$ Neurosci Res 2011; 89: 1342-1350.

57. Meyer U, Feldon J, Schedlowski M, Yee BK. Immunological stress at the maternal-foetal interface: a link between neurodevelopment and adult psychopathology. Brain Behav Immun 2006; 20: 378-388.

58. Meyer U, Schwendener S, Feldon J, Yee BK. Prenatal and postnatal maternal contributions in the infection model of schizophrenia. Exp Brain Res 2006; 173: 243-257.

59. Smith SE, Li J, Garbett K, Mirnics K, Patterson PH. Maternal immune activation alters fetal brain development through interleukin-6. J Neurosci 2007; 27: 10695-10702.

60. Li Q, Cheung C, Wei R, Cheung V, Hui ES, You Y, et al. Voxel-based analysis of postnatal white matter microstructure in mice exposed to immune challenge in early or late pregnancy. Neuroimage 2010; 52: 1-8.

61. Bitanihirwe BK, Peleg-Raibstein D, Mouttet F, Feldon J, Meyer U. Late prenatal immune activation in mice leads to behavioral and neurochemical abnormalities relevant to the negative symptoms of schizophrenia. Neuropsychopharmacology 2010; 35: 2462-2478.

62. Cardon M, Ron-Harel N, Cohen H, Lewitus GM, Schwartz M. Dysregulation of kisspeptin and neurogenesis at adolescence link inborn immune deficits to the late onset of abnormal sensorimotor gating in congenital psychological disorders. Mol Psychiatry 2010; 15: 415-425.

63. Dickerson DD, Wolff AR, Bilkey DK. Abnormal long-range neural synchrony in a maternal immune activation animal model of schizophrenia. J Neurosci 2010; 30: 1242412431.

64. Oh-Nishi A, Obayashi S, Sugihara I, Minamimoto T, Suhara T. Maternal immune activation by polyriboinosinic-polyribocytidylic acid injection produces synaptic dysfunction but not neuronal loss in the hippocampus of juvenile rat offspring. Brain Res 2010; 1363: 170-179.

65. De Miranda J, Yaddanapudi K, Hornig M, Villar G, Serge $\mathrm{R}$, Lipkin WI. Induction of Toll-like receptor 3-mediated immunity during gestation inhibits cortical neurogenesis and causes behavioral disturbances. MBio 2010; 1 .

66. Hsiao EY, Patterson PH. Activation of the maternal immune system induces endocrine changes in the placenta via IL-6. Brain Behav Immun 2011; 25: 604-615.

67. Koshibu K, Levitt P, Ahrens ET. Sex-specific, postpuberty changes in mouse brain structures revealed by three-dimensional magnetic resonance microscopy. Neuroimage 2004; 22: 1636-1645.

68. Meyer U, Spoerri E, Yee BK, Schwarz MJ, Feldon J. Evaluating early preventive antipsychotic and antidepressant drug treatment in an infection-based neurodevelopmental mouse model of schizophrenia. Schizophr Bull 2010; 36: 607-623.

69. Piontkewitz $Y$, Arad M, Weiner I. Risperidone administered during asymptomatic period of adolescence prevents the emergence of brain structural pathology and behavioral abnormalities in an animal model of schizophrenia. Schizophr Bull 2011; 37: 1257-1269.

70. Richtand NM, Ahlbrand R, Horn P, Stanford K, Bronson SL, McNamara RK. Effects of risperidone and paliperidone pretreatment on locomotor response following prenatal immune activation. J Psychiatr Res 2011; 45: 1194-1201.

71. Piontkewitz $\mathrm{Y}$, Assaf $\mathrm{Y}$, Weiner I. Clozapine administration in adolescence prevents postpubertal emergence of brain structural pathology in an animal model of schizophrenia. Biol Psychiatry 2009; 66: 1038-1046. 